\title{
Influence of F-18 FDG radiotracer application on image quality and SUV values when performing PET / CT study
}

\author{
Uticaj aplikacije F-18 FDG radiotrasera na kvalitet \\ snimaka i SUV vrijednosti kod izvođenja PET/CT \\ studije
}

Nusret Salkica ${ }^{1}$, Halil Ćorović ${ }^{1}$, Safet Hadžimusić ${ }^{1}$, Adel Brčaninović ${ }^{2}$

1 Clinic for Nuclear Medicine and Endocrinology, Clinical center of Sarajevo University, Bosnia and Herzegovina

2Clinic for Radiology and Nuclear Medicine of the University Clinical Center Tuzla, Bosnia and Herzegovina

Coressponding author: Nusret Salkica Klinika za nuklearnu medicinu i endokrinologiju KCUS, Bolnička 25, 71 000 Sarajevo, Email: nusret_nt@hotmail.com Received: 08.08.2020.

Accepted: 20.09 .2020 .

DOI: https://doi.org/10.48026/isnn.26373297.2020.11.1.1

\begin{abstract}
18F-FDG PET/CT is the most widely used diagnostic modality for detection of malignant disease. Beside the visual insight of FDG pathways into the human body, PET/CT can give valuable information based on the SUV values. The SUV is a quantitative parameter of metabolic activity. FDG application has 2 major impacts on PET/CT: qualitative aspect (visual insight of FDG in the body) and quantitative aspect (degradation of the SUV values). Based on the literature, FDG extravasation incidence is 31\% for all PET/CT studies and in $8 \%$ of all cases extravasation has been visually confirmed since the application place has been in the field of view. By constantly developing the technique, work methodology and increasing the quality control of the staff in the PET/CT department, the incidence of extravasation can be significantly reduced based on the results from the literature. In the case when paravenous injection is present on PET/CT images we can use certain software procedures to improve image quality and SUV quanitification.
\end{abstract}

Keywords: PET/CT, SUV, MIP, VR, 18-FDG

Apstrakt

18F-FDG PET/CT predstavlja najčešće korišteni dijagnostički modalitet za detekciju maligne bolesti. Pored vizuelnog uvida u raspodjelu FDG materijala u tijelu, PET/CT omogućava značajne informacije zasnovane na SUV mjerenjima. SUV predstavlja kvantitativni parametar metaboličke aktivnosti. Aplikacija FDG materijala za PET/CT utiče na dva vrlo važna aspekta - kvalitativni aspekt (vizuelni prikaz rasporeda FDG radiofarmaka za PET snimanje) i kvantitativni aspekt (SUV vrijednost može biti degradirana). Smatra se da je ekstravazacija prisutna kod 31\% svih PET/CT studija gdje je snimanjem obuhvaćeno područje glave do sredine femura, a u $8 \%$ slučajeva ekstravazacija je vizuelno zabilježena jer je mjesto aplikacije bilo u polju snimanja. Konstantnim razvojem tehnike, metodologije rada te povećanjem kontrole kvalieta rada osoblja na PET/CT odjelu te na osnovu rezultata iz literature incidenca ekstravazcije se može značajno smanjiti. U slučajevima već prisutne paravenske aplikacije postoje određeni algoritmi koji mogu spriječiti degradaciju kvaliteta snimaka uz poboljšanje SUV kvantifikacije.

Ključne riječi: PET/CT, SUV, MIP, VR, 18-FDG

Uvod

likovna metoda pozitronske emisione
tomografije (eng. Positron Emission
Tomography - PET) sa radioaktivnom 2-
deoxy-2-18fluoro-D-glukozom (FDG) i kompjuteriziranom tomografijom (eng. Computed Tomography - CT) integrirana u 18FFDG PET/CT predstavlja najsavremeniji dijagnostički modalitet za detekciju različitih 
vrsta malignih oboljenja. Zahvaljujući PET/CT snimanju moguće je odrediti staging i restaging bolesti, te pojavu recidiva osnovnog onkološkog oboljenja (1).

Napredak u tehnologiji je pored trodimenzionalnog vizuelnog prikaza rasporeda radioaktivnog materijala u tijelu pomoću fuzije slike omogućio uvođenje kvantifikacijskog parametra kojim je omogućeno praćenje aktivnosti i karakterizacije patoloških lezija u tijelu. Standardizirana vrijednost prihvata radiofarmaka (eng. Standardized Uptake Value SUV) predstavlja kvanitativni pokazatelj prihvata radioaktivnog materijala $\mathrm{u}$ tumorsku leziju. Najčešće korišten materijal za snimanje tumora pomoću PET/CT metode je 18F-FDG koji reflektira tumorski metabolizam glukoze, te je na osnovu fizikalnih osobina predstavljen kao marker tumorskog metabolizma. $\mathrm{Na}$ osnovu SUV vrijednosti moguće je odrediti stepen malignosti lezije. Poznato je da agresivniji tumori posjeduju povećan prihvat FDG materijala, te samim tim i povećane SUV vrijednosti (2).

SUV kalkulacija zavisi od velikog broja podataka: aktiviteta doze radiofarmaka, vremena pripreme $i$ aplikacije doze, veličine ostatnog aktiviteta doze nakon aplikacije i vremena mjerenja ostatne aktivnosti. Sama aplikacija FDG radiofarmaka vrši se intravenski (iv) putem braunile. Nakon aplikacije radiofarmaka braunila se ispire fiziološkom otopinom kako bi se prevenirala pojava rezidualnog aktiviteta jer cjelokupna aplikacija radioaktivnog materijala u cirkulaciju pacijenta rezultira stvarnim SUV vrijednostima. Aplikacija djelomične doze (paravenozna aplikacija) stvara nesklad između parametara pripremljene i aplicirane doze koji dovode do pogrešnog očitanja SUV vrijednosti. Kvalitet snimaka PET/CT kod pogrešno izvedene aplikacije može biti degradiran usljed pojačanog prisustva FDG materijala u polju snimanja.

Neadekvatna aplikacija PET trasera nije rijetka, ali je često neprimjetna jer se mjesta aplikacije radiofarmaka nalaze van skeniranog područja (položaj ruku iznad glave). Za razliku od drugih vrsta medicinskih pripravaka koji se apliciraju intravenskim putem (jodna kontrastna sredstva, hemoterapija itd), PET traseri se daju u jako malim zapreminama pa je pojava boli ili nekih drugih nelagodnosti rijetka od strane pacijenta ili inžinjera medicinske radiologije (3).

Aplikacija FDG materijala za PET/CT utiče na dva vrlo važna aspekta:

1. kvalitativni aspekt (vizualni prikaz rasporeda FDG radiofarmaka za PET snimanje može biti poremećen usljed loše aplikacije radiotrasera)

2. kvantitativni aspekt (SUV vrijednost može biti degradirana usljed netačno aplicirane doze radiofarmaka)

Prema podacima studije "US Nuclear Medicine and PET Imaging Systems Market" blizu 12500 PET/CT studija se obavi dnevno u Sjedinjenim Američkim Državama. Procjene kažu da se desi oko $10 \%$ infiltracijskih aplikacija u okolna tkiva (prijašnje studije govore o incidenci do 15,2\%). Naučnici smatraju da nije svaka od ovih aplikacija negativna po pacijenta i njegov dijagnostičko-terapijski menadžment. Međutim, temeljnom analizom zaključuje se da jedan dio ovih studija nije interpretabilan (4).

Kada je u pitanju kvalitativni aspekt neadekvatne aplikacije radiofarmaka, mjesto aplikacije često nije u polju snimanja tako i da sama neadekvatna aplikacija može proći nezapaženo. Glavni faktor koji pokazuje da je riječ o infiltraciji je smanjen doprinos signala slike ili u konačnici nerealne SUV vrijednosti za pojedine organe kao npr. mozak, mokraćni mjehur ili jetru.

Najveći broj PET/CT studija sa 18F-FDG radiofarmakom vrši se kod onkoloških pacijenata. U većini slučajeva riječ je o protokolu snimanja cijelog tijela od glave do sredine femura (eng. Whole Body PET/CT-WB PET/CT). Kod ovakvog snimanja ruke pacijenta (najčešće mjesto i.v. aplikacije je kubitalna jama) su iznad glave (izvan vidog polja) pa neadekvatna aplikacija često ostane neprimjetna. Ovakve aplikacije u $95 \%$ slučajeva nisu vidljive i prolaze bez značajnih posljedica po finalni nalaz (5).

Izuzetak snimanja WB PET/CT sa spuštenim rukama su protokoli snimanja karcinoma glave i vrata, mozga i trupa kod nekih neuroendokrinih tumora ili pak pacijenti koji nisu u stanju držati ruke iznad glave tokom snimanja (6).

Kada je mjesto aplikacije u polju snimanja (ruke pored tijela) kod snimanja karcinoma glave i vrata, te kada nije moguće držati ruke iznad glave 
ili kod izvođenja PET/CT snimanja od glave do prstiju (eng. Total Body PET/CT-TB PET/CT) kod malignog melanoma, multiplog mijeloma, karcinoma kosti ili kod metastatske bolesti perpendikularnog skeleta, paravenozna aplikacija može dovesti do potpune degradacije PET/CT snimka koji postaje neinterpretabilan. Dodatno, pored kvalitativne degradacije, kvantifikacija snimaka (SUV mjerenje) je također neizvodiva te se u slučaju masivne ekstravazacije sa degradacijom kvaliteta PET snimaka i SUV vrijednosti treba ponoviti sljedećih dana (7).
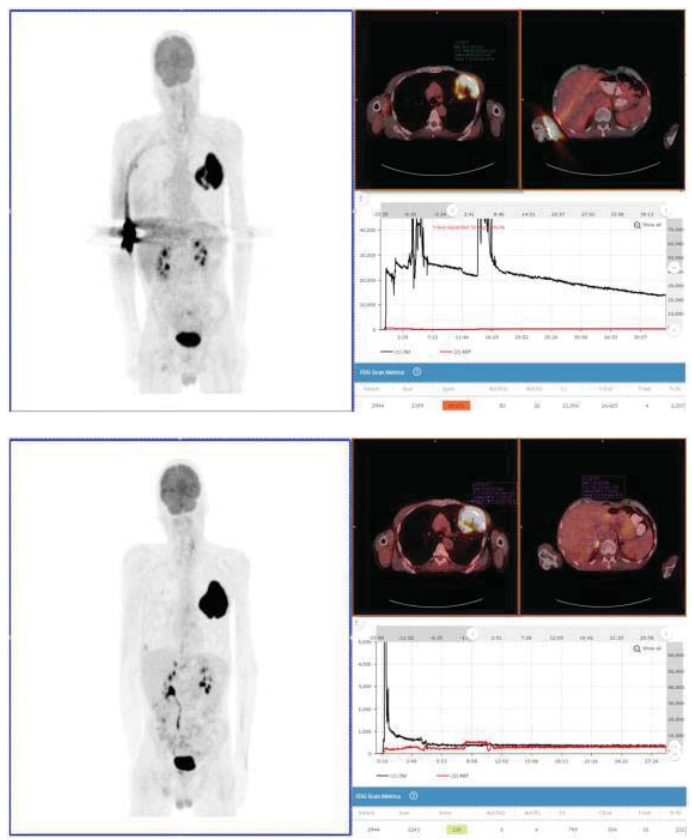

Slika br. 1. MIP WB PET prikaz masivne paravenske aplikacije FDG materijala - gornji red i MIP WB PET prikaz uredne aplikacije FDG materijala - donji red. TAC krivulje pokazuju razlike u vrijednostima za dvije PET studije kod istog pacijenta.

Pretpostavlja se da je ekstravazacija prisutna kod 31\% svih WB PET/CT studija gdje je snimanjem obuhvaćeno područje glave do sredine femura, a u $8 \%$ slučajeva ekstravazacija je zabilježena jer je mjesto aplikacije bilo u polju snimanja (8).

Analizom podataka iz studije "Fdg dose extravasations in PET/CT: frequency and impact on SUV measurements" SUV vrijednosti drastično se mijenjaju u slučaju masivne ekstravazacije. U 10,5\% slučajeva ekstravazacije, SUV vrijednost jetre i medijastinuma je promijenjena za $11,7 \%$ i 9,3\% (9).
Metodološka analiza obuhvatila je publikacije zadnje dekade sa najznačajnijim dostignućima iz oblasti tehnologije aplikacije radioaktivnog materijala za PET/CT studiju. U radu su korištene studije koje su istraživale automatski sistem pripreme i aplikacije PET radiofarmaka, termalne senzore za procjenu doze radioaktivnosti kao i studije koje se zadnjih godina bave mogućnostima primjene umjetne inteligencije u procjeni $i$ eliminaciji pojave ekstravazacije prilikom aplikacije PET radiotrasera. $\mathrm{Na}$ osnovu ovih kriterija 11 studija je prikazano u radu.

Diskusija

Rezultati studije "Impact of an 18F-FDG PET/CT Radiotracer Injection Infiltration on Patient Management-A Case Report" ukazuju na značaj detekcije ekstravazacije FDG radioaktivne doze kod PET/CT studije. Ekstravazacija negativno utiče na kvalitet PET/CT studije dok vrijednosti SUV mjerenja pokazuju odstupanja od standardnih. Naučnici smatraju da kod ovakvih situacija može biti korisno još jedno PET/CT snimanje 120-180 minuta nakon aplikacije. Ukoliko je riječ o masivnim ekstravazacijama, ukoliko se prati efekat terapije (pacijent je prethodno izvršio PET/CT snimanje-kontrolni PET/CT), najbolja opcija je ponoviti PET/CT pretragu (10).

Razvojem tehnologije pojava ekstravazacija je smanjena. Pored manuelne aplikacije radiotrasera u praksu su uvedeni mobilni automatski injektori koji su prikopčani na infuzioni sistem te kontinuirano vrše aplikaciju radiotrasera uz propiranje braunile pomoću fiziološke otopine. $\mathrm{Na}$ ovaj način aplicira se gotovo cjelokupna doza uz minimalni rezidualni aktivitet u šprici što poboljšava SUV kvantifikaciju. Aplikacija radiofarmaka traje nekoliko minuta tako da je u slučaju pojave bola omogućeno prekidanje aplikacije i preveniranje pojave masivne ekstravazacije. Radijacijsko opterećenje za osoblje je drastično smanjeno (11).

Novije studije ističu značaj prevencije ekstravazacije različitim tehnološkim rješenjima. Jedno od rješenja je upotreba gama scintilacionih detektora. Studija "Towards real-time topical detection and characterization of FDG dose infiltration prior to PET imaging" ističe 
potencijal postavljanja senzora na kožu i dinamsko mjerenje krivulje emitiranja zračenja kroz period od aplikacije do početka snimanja (eng. Time-Activity Curve-TAC). TAC mjerenja prikupljaju podatke emitiranog zračenja tumora i porede ga sa SUV vrijednostima samog tumora. Senzori za TAC mjerenje su postavljeni i za područje gdje je izvršena aplikacija radiofarmaka te je na ovaj način zabilježena pojava ekstravazacije. Ovaj metod omogućava prevenciju, ali i ranu detekciju ekstravazacije. TAC mjerenja pored preventivne uloge imaju značajan uticaj na poboljšanje kontrole kvaliteta rada PET/CT odjeljenja.

$\mathrm{Na}$ tržištu su prisutni i posebni softverski sistemi koji također rade na principu registriranja TAC krivulje. Značaj Lara sistema istaknut je u studiji "Quality Improvement Initiatives to Assess and Improve PET/CT Injection Infiltration Rates at Multiple Centers". Rad Lara softverskog sistema sličan je radu kod prvobitnih TAC sistema s tim što su senzori detekcije zračenja postavljeni oko $7 \mathrm{~cm}$ proksimalno od mjesta aplikacije te na identično mjesto na drugom ekstremitetu. Nakon intravenske aplikacije radiofarmaka mjere se vrijednosti impulsa i kreiraju TAC krivulje za oba ekstremiteta. Vrijednosti do 200 impulsa se smatraju urednim, dok su vrijednosti od 1000 i više impulsa znak da je došlo do paravenske aplikacije. Ovaj sistem rada inžinjeru medicinske radiologije može ukazati na pojavu ekstravazacije prije same PET/CT akvizicije, te može biti od velikog značaja za unapređenje rada osoblja na PET/CT odjelu.

Muzaffar i saradnici su u studiji "Novel method to detect and characterize 18F-FDG infiltration at the injection site: A single-institution experience" dodatno unaprijedili upotrebu TAC senzora kod ekstravazacije sa nalazima koje su interpretirali ljekari specijalisti nuklearne medicine. Istraživači su zaključili da je 38\% ekstravazacija minorno, te da ne utiče na kvalitet PET/CT snimka i vrijednost SUV-a. TAC senzori su otkrili $55 \%$ slučajeva ekstravazacije, razlika u nastaloj incidenci je u pojavi ekstravazacija van vidnog polja. Nakon analize stanja uvedena je u sistem nadzora aplikacije radiofarmaka koji je doveo do drastičnog pada ekstravazacijskih aplikacija (12).
Posljednjih godina poseban fokus stavljen je na procjenu ekstravazacijske doze kod uočenih paravenoznih aplikacija. Nekoliko metoda korišteno je za proračun doze koja nije otišla u cirkulaciju pacijenta kako bi se proračunala adekvatna SUV vrijednost. Studija "Correction for FDG PET dose extravasations: Monte Carlo validation and quantitative evaluation of patient studies" ukazuje na promjene SUV vrijednosti za oko $22 \%$ kod ekstravaziranih slučajeva. Ovako visoke promjene SUV vrijednosti naročito su značajne za organe koji inače pokazuju niske SUV vrijednosti te bi se neprepoznavanjem ekstravazacije SUV vrijednosti mogle podcijeniti. Nekoliko je metoda koje naučnici ističu, a najjednostavnija metoda izračuna ekstravazata je manuealno iscrtavanje regije interesa (eng. Region of Interest-ROI) za područje ekstravazata te ista takva regija na kontralateralnom ekstremitetu. Nakon crtanja ROI koristi se metoda subtrakcije dvije regije te se mjeri broj impulsa. Moguće je i dobijanje informacija o volumenu dvije regije interesa te proračun odnosa ekstravazata od ukupnog apliciranog volumena (13).

Topikalni senzori koji registriraju TAC krivulje pored 18 F-FDG radioaktivnog materijala mogu biti korišteni i za druge pozitronske emitere. $U$ studiji " Topical Sensor for the Assessment of Injection Quality for 18F-FDG, 68Ga-PSMA and 68Ga-DOTATATE Positron Emission Tomography" ističe se mogućnost prevencije ili čak korekcije paravenske aplikacije i drugih PET radiotrasera kao što su 68Ga-PSMA and 68GaDOTATATE i drugi. Pored značaja TAC senzora naučnici ističu da automatski injektori, mobilni ili stacionarni značajno smanjuju incidencu paravenoznih aplikacija u poređenju sa ručnim načinom aplikacije (14).

Studija "Assessing and reducing PET radiotracer infiltration rates: a single center experience in injection quality monitoring methods and quality improvement" ukazuje na veliki značaj detekcije ekstravazacije radiofarmaka u cilju poboljšanja kvaliteta rada PET/CT odjela. Naučnici smatraju da čak $63 \%$ slučajeva ekstravazacija nije uopšte vidljivo na PET/CT snimcima. Pored upotrebe vanjskih senzora procjena SUV vrijednosti za područje jetre kao referalnog organa može upućivati na prisustvo ekstravazacije koja se nalazi izvan vidnog polja (15). 
Razvoj tehnologije umjetne inteligencije - UI (eng. Artificial Intelligence - AI) unaprijedio je polje molekularnog imidžinga. Pored primjene AI u slikovnoj tehnologiji, ostvaren je ogoroman napredak na polju implementacije AI u poboljšanje kvaliteta aplicirane doze. Početni stadij kombinacije AI i metodologije procjene kvaliteta aplicirane doze u studiji "Classification of PET/CT Injection Quality Using Deep Learning Techniques and External Radiation Detectors" prikazuje pouzdanost metode od 80$85 \%$ (16).

Dodatni razvoj neuralne mreže u kombinaciji sa TAC senzorima stvara temelj pouzdanog metoda procjene kvaliteta aplicirane doze. Naučnici rade i na razvoju alata korekcije neadekvatne aplikacije doze radiofarmaka. Preliminarni rezultati u studiji "Classification of infiltrated injections during PET/CT imaging applying deep learning technique" ocjenjuju da je uspješnost procjene kvaliteta injekcione metode podignuta na 94,58\%. Pouzdan softverski modalitet stvara preduslove za širu kliničku komercijalnu upotrebu u skorijoj budućnosti (17).

\section{Zaključak}

Ekstravazacija PET trasera nije rijetka. Mjesto aplikacije (kubitalna jama) često nije u polju snimanja tako da paravenske aplikacije FDG-a mogu proći neopaženo. Glavni pokazatelj ovakvih ekstravazacija su SUV vrijednosti koje odstupaju od standardnih SUV vrijednosti. Razvoj tehnologije doveo je do poboljšanja kvaliteta aplikacije radiofarmaceutika. Automatski injektori dokazano povećavaju kvalitet aplicirane doze uz smanjenje incidence ekstravazacije. Postoje novi softverski algoritmi koji mogu eliminirati degradaciju kvaliteta PET/CT snimaka usljed paravenske aplikacije. Ovo su algoritmi koji su u stanju odrediti volumen eksudata kako bi se prilagodila SUV vrijednost novonastaloj situaciji. Kontinuiran razvoj metodologije rada praćen savremenim tehnologijama omogućit će smanjenje incidence neželjenih događaja u koje spada i esktravazacija radioaktivnog materijala na PET/CT odjeljenju.

\section{Reference}

1. Almuhaideb A, Papathanasiou $\mathrm{N}$, Bomanji J. 18F-FDG PET/CT imaging in oncology. Ann Saudi Med.
2011;31(1):3-13. doi:10.4103/02564947.75771.

2. Paidpally V, Chirindel A, Lam S, Agrawal N, Quon H, Subramaniam RM. FDG-PET/CT imaging biomarkers in head and neck squamous cell carcinoma. Imaging Med. 2012;4(6):633-647. doi:10.2217/iim.12.60.

3. Wong TZ, Benefield T, Masters S, Kiser JW, Crowley J, Osborne D et al. Quality Improvement Initiatives to Assess and Improve PET/CT Injection Infiltration Rates at Multiple Centers. J Nucl Med Technol. 2019;47(4):326-331. doi:10.2967/jnmt.119.228098..

4. Daher N. US Nuclear Medicine and PET Imaging Systems Market, 2014. https://cds.frost.com/p/71559/\#!/pp $\mathrm{t} / \mathrm{c}$ ? id=NCFC-01-00-

0000\&hq $=$ US $\% 20$ Nuclear $\% 20$

Medicine \%20and\%20PET\%20Imaging $\% 20$ Systems $\% 20$ Market.

5. Von Schulthess GK, Steinert HC, Hany TF. Integrated PET/CT: current applications and future directions. Radiology 238, 2006; 405-422.

6. Delbeke D, Coleman RE, Guiberteau MJ, Brown ML, Royal HD, Siegel BA et al. Procedure guideline for tumor imaging with 18F-FDGPET/CT. J. Nucl.Med. 2006;47, 885-895.

7. Williams JM, Arlinghaus LR, Rani SD, Shone MD, Abramson VG, Pendyala P et al. Towards real-time topical detection and characterization of FDG dose infiltration prior to PET imaging. Eur J Nucl Med Mol Imag. 2016; 43:2374-2380. doi: 10.1007/s00259016-3477-3.

8. Coleman RE, Hillner BE, Shields AF, Duan F, Merlino DA, Hanna LG et al. PET and PET/CT reports: observations from the National Oncologic PET Registry. J Nucl Med. 2010;51(1):158-63. doi: 10.2967/jnumed.109.066399.

9. Osman MM, Muzaffar R, Altinyay ME, Teymouri C. Fdg dose extravasations in pet/ct: frequency and impact on suv measurements," Frontiers in oncology, 2011; 1, 41. 
10. Kiser JW, Crowley JR, Wyatt DA, Lattanze RK. Impact of an 18F-FDG PET / CT Radiotracer Injection Infiltration on Patient Management-A Case Report. Frontiers in Medicine. 2018;5:1-5. doi:10.3389/fmed.2018.00143.

11. Lecchi M, Lucignani G, Maioli C, Ignelzi G, Del Sole A. Validation of a new protocol for ${ }^{18} \mathrm{~F}-\mathrm{FDG}$ infusion using an automatic combined dispenser and injector system. Eur J Nucl Med Mol Imaging. 2012;39(11):1720-9. doi: 10.1007/s00259-012-2174-0.

12. Muzaffar R, Frye SA, McMunn A, Ryan K, Lattanze R, Osman MM. Novel method to detect and characterize 18FFDG infiltration at the injection site: A single-institution experience. J Nucl Med Technol. 2017;45(4):267-271. doi:10.2967/jnmt.117.198408.

13. Silva-Rodríguez J, Aguiar P, Sánchez M, Mosquera J, Luna-Vega V, Cortés J et al. Correction for FDG PET dose extravasations: Monte Carlo validation and quantitative evaluation of patient studies. Med. Phys. 2014; 41: 052502. doi:10.1118/1.4870979.

14. Sanchez S, Currie GM. Topical Sensor for the Assessment of Injection Quality for 18F-FDG, 68Ga-PSMA and 68GaDOTATATE Positron Emission Tomography. J Med Imaging Radiat Sci. 2020;51(2):247-255. doi:10.1016/j.jmir.2020.01.003.

15. Osborne DR, Acuff SN, Fang M, Weaver $\mathrm{MD}, \mathrm{Fu}$ Y. Assessing and reducing PET radiotracer infiltration rates: A single center experience in injection quality monitoring methods and quality improvement. BMC Med Imaging. 2020;20(1):1-7. doi:10.1186/s12880-020-0408-3.

16. Tumpa T, Acuff S, Carr C, Baxter E, Osborne DR. Classification of PET/CT Injection Quality Using Deep Learning Techniques and External Radiation Detectors. J Nucl Med. 2018;59(1): 33.

17. Tumpa TR, Acuff SN, Osborne DR. Classification of infiltrated injections during PET/CT imaging applying deep learning technique. Proc-Int Conf Tools with Artif Intell ICTAI. 2019; 17811785. doi:10.1109/ICTAI.2019.00267. 